\title{
Cotidiano
}

\section{DESENVOLVIMENTO REGIONAL: UM ESTUDO NA REGIÃO METROPOLITANA DO CARIRI}

Raimundo Pereira Aguiar Neto (1)

Michele da Silva Teixeira (2)

\begin{abstract}
Resumo
O Cariri Cearense vive o avanço através de investimento nos setores de turismo, indústria, segurança, agricultura, transporte, saúde e infra-estrutura. A recém criada Região Metropolitana do Cariri - RMC, composta pelas cidades de Crato, Juazeiro do Norte, Barbalha, Santana do Cariri, Nova Olinda, Caririaçu, Farias Brito, Missão Velha e Jardim, destacam-se no estado pelo seu potencial econômico notável, o que levará o governo federal a injetar nos próximos cinco anos cerca de 132 milhões de reais para fortalecimento dessas cidades cearenses, fato que irá favorecer ainda mais a economia do estado gerando empregos e atraindo investimentos. Como sinal mais intenso do desenvolvimento da RMC, temos os projetos federais aqui executados, objetivando o crescimento compartilhado, levando em consideração as diferenças entre as cidades e suas potencialidades. $\mathrm{O}$ presente estudo tem como objetivo principal identificar, através de uma abordagem qualitativa e pesquisa bibliográfica, os principais investimentos para a consolidação dessa Região Metropolitana, e obteve êxito ao documentar e expressar para a população interessada os motivos pelos quais o Cariri tornou-se nos últimos anos um canteiro de obras, no entanto, pode-se notar claramente que para se estabelecer uma política de desenvolvimento em meio urbano, não é suficiente apenas investimentos em geração de emprego, renda e infra-estrutura, mas tornam-se necessárias ações globais de melhoria da qualidade de vida, políticas habitacionais e projetos de desenvolvimento das cidades.
\end{abstract}

Palavras- Chave: Cariri. Desenvolvimento. Região metropolitana.

\section{Introdução}

Uma lei complementar de junho de 2009 deu origem à Região Metropolitana do Cariri, que surgiu da necessidade de possibilitar o desenvolvimento unificado do chamado CRAJUBAR e de outras seis cidades da região, o que totaliza uma população superior a quinhentos e sessenta mil habitantes. Representantes do governo do estado e das administrações municipais discutiram as ações estratégicas para viabilizar o crescimento dessa região cearense. 
As cidades do sul cearense conseguiram nos últimos anos, grandes avanços em todos os setores, e a população reconhece a necessidade de unificar a região para que todos os municípios possam se desenvolver igualmente. Não só no âmbito turístico e religioso como acontece em Juazeiro do Norte, mas também na potencialidade de cada município integrante da RMC. Diversos seguimentos da sociedade discutiram ações estratégicas para que a região metropolitana do Cariri se tornasse uma realidade.

No território metropolitano está previsto um conjunto de ações e projetos que reforçam a natureza metropolitana, pois atendem regionalmente todas as cidades envolvidas, tanto no estado do Ceará como nos estados vizinhos.

O presente estudo tem como objetivo principal, através de pesquisa bibliográfica e de cunho qualitativo, identificar os principais investimentos de iniciativa pública ou privada para a consolidação da Região Metropolitana do Cariri, a fim de documentar e expressar para a população interessada os motivos pelos quais o Cariri tornou-se nos últimos anos em um verdadeiro canteiro de obras.

Devido ao intenso desenvolvimento pelo qual a região do Cariri tem passado, deve-se a justificativa de escolha do tema apresentado. E apresenta-se a seguinte problemática, como fazer para que o desenvolvimento dessa região seja melhor distribuído e que todas as cidades envolvidas possam desfrutar de um crescimento unificado trazendo melhor qualidade de vida para a população?

Ao longo dos próximos anos, cento e trinta e dois milhões de reais serão investidos na região nos setores de infraestrutura urbana, apoio ao setor econômico e fortalecimento institucional, o objetivo é permitir que os municípios se desenvolvam de forma compartilhada apesar das diferenças que existem de uma cidade para a outra.

Ser região metropolitana significa estabelecer planos conjuntos, respeitando as assimetrias de cada cidade, pois é evidente que todos os municípios da RMC não estão no mesmo patamar, seja de população, seja de oportunidade de emprego e renda, e esse é um desafio, trabalhar com assimetrias fazendo com que a região alcance resultados que possam ser melhores distribuídos.

Mesmo possuindo uma economia representativa para o estado do Ceará, a criação de tal região foi bastante protelada, e agora, inúmeras oportunidades de negócios emergem e evidenciam o Cariri, e o pensamento isolado de cada município integrante deve agora ser ampliado para um horizonte mais amplo vislumbrando benefícios de região metropolitana como um todo, facilitando o desenvolvimento desta.

Para a população não resta dúvida de que o desenvolvimento é importante, porém ele deve representar-se não somente no tocante ao sistema econômico, mas também incluir o desenvolvimento social, o desenvolvimento de políticas públicas de educação, da saúde, de assistência social, do trato com o meio ambiente, enfim, contemplando todos os setores e não somente o setor industrial e econômico da região. 


\section{Região Metropolitana do Cariri e Seu Potencial}

O Cariri Cearense vive as expectativas de desenvolvimento e investimento nos setores de turismo, indústria, segurança, agricultura, transporte e saúde. Estes são os pontos destacados por seus representantes, com a criação da Região Metropolitana do Cariri (RMC), que abrange um total de nove cidades; Crato, Juazeiro do Norte e Barbalha, consideradas as principais cidades, seguidas de suas vizinhas como Santana do Cariri, Nova Olinda, Caririaçu, Farias Brito, Missão Velha e Jardim. Dados do IBGE mostram que a cidade de Juazeiro, a maior cidade integrante da RMC do Cariri, possui uma população de 250.000 habitantes, e a RMC em seu total, possui uma população superior a 540.000 habitantes.

Os investimentos ficarão em volta de 132 milhões, e deverão ser efetivados em até cinco anos, através de um projeto do governo do estado do Ceará intitulado de Cidades do Ceará - Cariri Central, onde é reforçado por Cartaxo (2009) ao afirmar que "a Região Metropolitana do Cariri é uma evolução do Projeto Cidades do Ceará e deve contribuir para aprimorar os mecanismos de planejamento e fortalecimento da região".

Segue quadro resumido dos investimentos:

QUADRO I - CUSTOS POR COMPONENTES DO PROJETO

\begin{tabular}{|c|c|c|c|c|c|}
\hline \multirow{3}{*}{ COMPONENTES } & \multicolumn{5}{|c|}{ CUSTO DO PROJETO (US\$) } \\
\hline & BIRD & ESTADO & \multicolumn{3}{|c|}{ TOTAL } \\
\hline & VALOR & VALOR & VALOR & $\begin{array}{c}\% \\
\text { BIRD } \\
\end{array}$ & $\begin{array}{c}\% \\
\text { ESTADO } \\
\end{array}$ \\
\hline $\begin{array}{l}\text { 1. Investimentos em Infraestrutura Física na Região } \\
\text { do Cariri Central }\end{array}$ & $19.486 .600,00$ & $13.607 .300,00$ & $33.093 .900,00$ & 29,5 & 20,6 \\
\hline $\begin{array}{l}\text { 2. Investimentos em Inovações e Apoio ao Setor } \\
\text { Privado na Região do Cariri Central }\end{array}$ & $17.306 .100,00$ & $6.392 .700,00$ & $23.698 .800,00$ & 26,2 & 8,7 \\
\hline $\begin{array}{l}\text { 3. Investimentos na Gestão Regional e no } \\
\text { Fortalecimento Institucional da Região do Cariri } \\
\text { Central }\end{array}$ & $9.207 .300,00$ & - & $9.207 .300,00$ & 14,0 & - \\
\hline TOTAL & $46.000 .000,00$ & $20.000 .000,00$ & $66.000 .000,00$ & 69,7 & 30,3 \\
\hline
\end{tabular}

Fonte: Governo do Estado do Ceará

A região tem um potencial econômico notável, e poderá se fortalecer como um pólo educacional do Ceará, o que irá favorecer a economia local gerando empregos, atraindo investimentos e imigrantes de outros estados que deverão impulsionar ainda mais o avanço regional.

Como já foi mencionado, o crescimento ocorre com mais intensidade em pontos localizados, concentrando-se em algumas localidades. O mesmo acontece com a localização da população, que se 
estabelecem, via de regra, às margens das cidades metrópoles criando pólos de desenvolvimento, assim o crescimento por torna-se positivo para o desenvolvimento do país como um todo.

Como terceiro maior pólo calçadista do país, que surgiu da demanda por sandálias de dedo, os empresários e representantes do Sindicato das Indústrias de Calçados e Vestuário da Região do Cariri, esperam que para os próximos anos os investimentos dobrem. Contudo a atividade industrial vem se expandindo, e existem mais de 200 fábricas funcionando na cidade, com diversos tipos de sandália: de moda, ou produzidas com EVA, borracha ou PVC.

[...] A região do Cariri, principalmente Juazeiro do Norte, onde se encontra o maior número de fábricas de calçados da região, representa uma das maiores forças da economia no Brasil neste setor. É o terceiro polo calçadista do País. São mais de 16 mil empregos gerados a partir das centenas de empresas implantadas em Juazeiro. (JOTALOPES, 2011, p. 1)

\section{Os Desafios do Crescimento}

Como sinal mais intenso do desenvolvimento da região do Cariri, existem alguns projetos considerados prioritários que se encontram em andamento como o Aterro Consorciado, o Hospital Regional e o Ceasa. Outros setores que merecem maiores investimentos como o Turismo Regional e a Indústria Calçadista, desempenham papel fundamental para a região, e se trabalhados de forma correta, poderão melhor unificar o crescimento regional. Para Cartaxo $(2010$, p. 01), “[...] hoje é comum uma pessoa trabalhar no Juazeiro, morar no Crato e estudar em Barbalha e essa dinâmica metropolitana deve ser aproveitada para o desenvolvimento da Região".

O objetivo da criação dessa região metropolitana deve ser o crescimento compartilhado, levando em consideração as diferenças entre as cidades e suas potencialidades, pois as assimetrias são evidentes e políticas conjuntas devem priorizar o desenvolvimento da região como um todo.

O primeiro grande desafio da Região Metropolitana do Cariri é conseguir integrar os municípios numa política de desenvolvimento sustentável. Falta sentar e discutir metas e prioridades, com a apresentação de projetos de desenvolvimento econômico, criação de uma Zona de Processamento e Exportação de Produtos Industrializados (ZPE), o que irá diminuir a carga tributária dos produtos da região. (SANTANA, 2009 p. 01).

A RMC possui muitos pontos que a favorecem no que tange ao seu crescimento, porém vale ressaltar a respeito de sua posição geográfica. Localizada no Nordeste do país, a referida região encontra-se eqüidistante de todas as capitais do Nordeste de brasileiro. 
FIGURA I - MAPA DA REGIÃO DO CARIRI CENTRAL

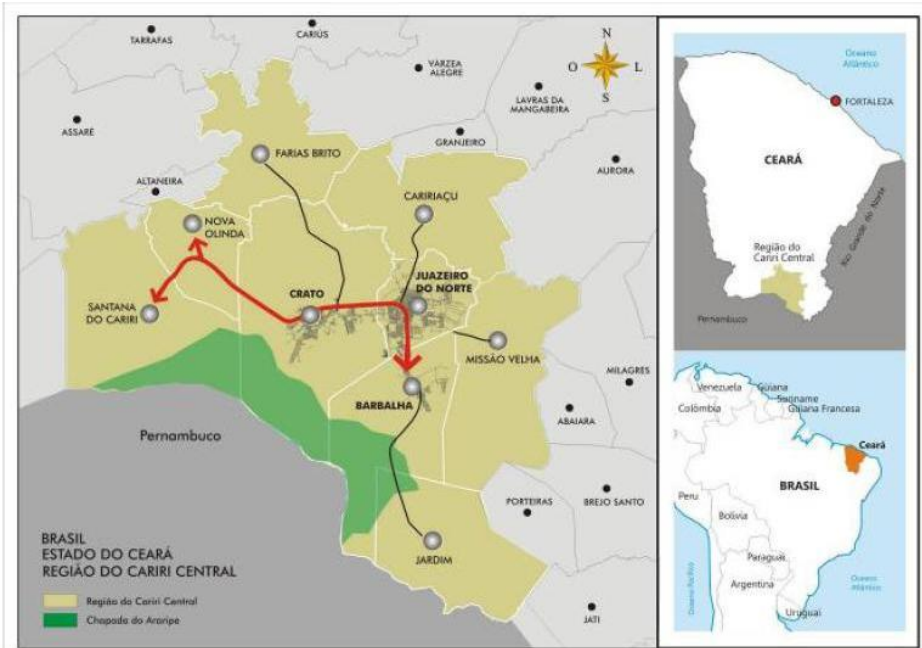

Fonte: Governo do Estado do Ceará

Tal fato dá destaque ao Aeroporto de Juazeiro do Norte, Orlando Bezerra de Menezes, que devido à sua localização estratégica atende às regiões Centro Sul do Ceará, Noroeste de Pernambuco, Alto Sertão da Paraíba e Sudoeste do Piauí, representando um dos principais instrumentos para o desenvolvimento econômico da região.

Em face das muitas potencialidades do Cariri, entre elas o turismo religioso, os negócios, os tesouros paleontológicos da Serra do Araripe, entre outras, o referido aeroporto tem sido um dos que mais cresce em números no Brasil. No ano de 2009, o Aeroporto de Juazeiro foi apontado como o que mais cresceu no país, registrando um crescimento de $45 \%$ na demanda de passageiros em relação ao ano de 2009. "A cada ano, as romarias atraem mais e mais devotos. Além disso, Juazeiro do Norte está inserida numa região industrial e possui várias universidades", destaca o superintendente da INFRAERO Juazeiro do Norte, Roberto Germano de Souza Araújo.

Ainda com todos esses fatos apontados, o Aeroporto de Juazeiro, apesar de já ter passado por algumas melhorias no último ano, ainda precisa de mudanças mais significativas em sua infraestrutura que poderão alavancar de vez o crescimento da região no qual está inserido.

Segundo a Empresa Brasileira de InfraEstrutura Aeroportuária - INFRAERO existe uma verba de $\mathrm{R} \$ 50.000 .000,00$ aprovada para investimentos no Aeroporto Juazeirense, porém, por impasses não divulgados, até a data de conclusão do presente estudo, esse valor ainda não havia sido liberado, fato que tem emperrado um desenvolvimento mais crescente que o já apresentado.

\section{Consequências do Crescimento}

O avanço das cidades metrópoles, que são Crato, Juazeiro do Norte e Barbalha, conduz para o bem conhecido fenômeno de crescimento de favelas e aumento de problemas sociais, implicando na 
má qualidade de vida da população e o êxodo rural. O que fica claro é que para se estabelecer uma política de desenvolvimento em meio urbano, não é suficiente apenas investimentos em geração de emprego e renda, mas tornam-se necessárias também ações globais de melhoria da qualidade de vida, políticas habitacionais e projetos de desenvolvimento das cidades.

Uma região pode crescer mais rapidamente do que as demais se empregar os insumos existentes de modo mais produtivo ou importando tecnologia mais avançada... Se for correta a tese de que "aprende-se fazendo", então o progresso técnico estará concentrado nas regiões onde houver maior volume de investimento. (SOUZA, p.20)

Agora como região metropolitana, todos os municípios envolvidos precisam dar atenção especial a políticas públicas de apoio social, à saúde e educação, contemplando todos esses setores, para que a RMC realmente venha a trazer benefícios à população. Há alguns anos seguíamos os passos da região metropolitana de Fortaleza (RMF), porém hoje já temos nossos próprios indicadores no que diz respeito ao índice de desenvolvimento humano (IDH), que se torna de fundamental importância para mensurar os avanços de uma região metropolitana, e como podemos ver a baixo alguns dos municípios da RMC possuem índice parecido com os da capital.

QUADRO II - ÍNDICE DE DESENVOLVIMENTO HUMANO - RMF

\begin{tabular}{|c|c|c|}
\hline Município & IDH - M, 1991 & IDH - M, 2000 \\
\hline Fortaleza & 0,717 & 0,786 \\
\hline Maracanaú & 0,633 & 0,736 \\
\hline Caucaia & 0,611 & 0,721 \\
\hline Pacatuba & 0,622 & 0,717 \\
\hline Maranguape & 0,578 & 0,691 \\
\hline Eusébio & 0,579 & 0,684 \\
\hline Aquiraz & 0,537 & 0,670 \\
\hline
\end{tabular}

Fonte: ONU

QUADRO III - ÍNDICE DE DESENVOLVIMENTO HUMANO - RMC

\begin{tabular}{|c|c|c|}
\hline Município & IDH - M, 1991 & IDH - M, 2000 \\
\hline Crato & 0,616 & 0,716 \\
\hline Juazeiro do Norte & 0,596 & 0,697 \\
\hline Barbalha & 0,591 & 0,687 \\
\hline Jardim & 0,521 & 0,642 \\
\hline Nova Olinda & 0,519 & 0,637 \\
\hline Missão velha & 0,504 & 0,631 \\
\hline Santana do Cariri & 0,481 & 0,609 \\
\hline
\end{tabular}

Fonte: ONU 
No que diz respeito aos projetos de crescimento da região e a relação da RMC com o seu meio ambiente, também são necessários mais estudos e planejamentos, pois a maioria dos municípios estão em zona de preservação ambiental o que torna ainda mais complicada e difícil a implantação de projetos.

\section{O Crescimento Desordenado da Região}

O crescimento econômico vem ocorrendo de modo muito concentrado tanto no em aspectos setoriais como espacial. Enquanto a região metrópole cresce com altas taxas, as demais permanecem estagnadas e perdem cada vez mais a sua participação no entorno metropolitano, assim os fatores de produção, como capital e mão-de-obra, tendem a emigrar das cidades periféricas em direção do pólo, o que vem acontecendo com freqüência.

No interior da economia, em verdade, não poderia haver motivo para estudos específicos, em virtude da suposição da perfeita mobilidade dos fatores de produção, dos bens e serviços e das pessoas. Ela conduziria o sistema econômico ao equilíbrio, uma vez que se observassem desigualdades marginais e transitórias nos custos de produção, nos salários e nos preços dos bens. (SOUZA, p. 01.)

O correto seria o crescimento mais do que proporcional da região central, em relação às suas periféricas, o que traduziria um menor desenvolvimento da economia como um todo em curto prazo, porém com maiores benefícios a médio e longo prazo. A centralização do desenvolvimento, a partir do pólo principal, poderá ser prejudicada pela pobreza das demais regiões e pela ausência de estímulos ao surgimento de integração na RMC.

Desse modo, serão gerados futuramente problemas não só a nível econômico, mas também social e sanitário e a alternativa recomendável para manter o crescimento será a reestruturação das regiões periféricas o que gera insatisfação na região central.

O avanço das metrópoles, denominadas de CRAJUBAR (Crato - Juazeiro do Norte Barbalha), vêm atraindo empresas, o que de fato coopera com o desenvolvimento da RMC, porém os outros seis municípios não podem ficar parados no tempo assistindo o crescimento dessas três cidades, eles também devem disponibilizar terrenos mais baratos e de maior dimensão, ou respondendo a incentivos fiscais ou facilidades de transportes.

Como região metropolitana todos os municípios envolvidos devem compor um acordo de vantagens para atrair investimentos privados e públicos, afim de um crescimento uniforme levando em consideração as suas peculiaridades.

O documento ora apresentado constitui uma importante contribuição da Secretaria das Cidades ao processo de planejamento do desenvolvimento regional do Estado do Ceará. Esforços técnicos empreendidos há mais de três anos por profissionais de diferentes 
áreas, envolvendo distintos órgãos e representantes locais da sociedade civil e dos setores produtivos, permitiram que se desenhasse o escopo geral do Projeto de Desenvolvimento Econômico Regional do Ceará - Cidades do Ceará (Cariri Central), que visa apoiar e dinamizar as atividades produtivas locais identificadas como prioritárias para o desenvolvimento da região do Cariri Central, selecionada para atuação do Projeto. (CARTAXO, 2009. p. 07)

A rotina relativamente pacata dos moradores de grande parte da RMC contrasta com o ritmo de expansão do Cariri, que atinge números elevados o que prova o potencial da região. O crescimento do Cariri cearense é um retrato do vigor econômico regional que toma conta de parte do interior do estado. Assim, o processo de gradativa interiorização do crescimento, fez emergir um grande número de empresas regionais que precisam ser orientadas para que suas atividades não venham a cessar nos próximos anos.

De acordo com a socióloga e economista Tânia Bacelar, a região segue a uma lógica nacional de desenvolvimento das cidades de médio porte. Apesar de estar acima das estatísticas de crescimento e ser considerado um fenômeno, onde apenas o Produto Interno Bruto (PIB) de Juazeiro do Norte quase triplicou em um período de cinco anos, passando de R\$ 670 milhões em 2003, para um R\$ 1,9 bilhão em 2008, o Cariri ainda tem demandas por serviços básicos de infraestrutura. Em termos de gestão, falta mais interação entre os prefeitos da região (DIÁRIO DO NORDESTE, 2011).

QUADRO IV: PIB'S CEARÁ 2008

\begin{tabular}{|l||l||}
\hline \multicolumn{2}{|c||}{ Maiores PIB's do Ceará no Período de 2008 } \\
\hline \hline \multicolumn{1}{|c||}{ Cidades } & PIB \\
\hline \hline Fortaleza & $\mathrm{R} \$ 8.350 .622 .000,00$ \\
\hline Maracanaú & $\mathrm{R} \$ 3.121 .055 .000,00$ \\
\hline \hline Juazeiro do Norte & $\mathrm{R} \$ \mathbf{1 . 9 8 6 . 9 9 6 . 0 0 0 , 0 0}$ \\
\hline Caucaia & $\mathrm{R} \$ 1.952 .311 .000,00$ \\
\hline Sobral & $\mathrm{R} \$ 1.702 .060 .000,00$ \\
\hline
\end{tabular}

Fonte: Prefeitura Municipal de Juazeiro do Norte, 2009

O crescimento do PIB apontado PIB'S CEARÁ 2008 e citado anteriormente comprova que o PIB de Juazeiro do Norte subiu 157\% entre os anos de 2004 e 2008, ressaltando-se que no ano de 2008 esse crescimento surpreendeu destacando-se historicamente como o segundo maior crescimento entre os municípios do Estado do Ceará. São fatos como este que atraem cada vez mais empresários e 
investidores para a RMC, essas pessoas acreditam no potencial não somente da cidade de Juazeiro, conforme apontado, mas sim da RMC como um todo, que cresce acima da média nacional.

\section{Vantagens de ser Região Metropolitana}

Com o objetivo de combater a pobreza do Estado e reduzir o desequilíbrio entre a Região Metropolitana de Fortaleza e o interior, o governo do Estado do Ceará vem apontando o desenvolvimento regional como uma das suas prioridades, com foco em: Sociedade justa e solidária e economia para uma vida melhor.

A estratégia da Secretaria das Cidades é está à frente de um programa de desenvolvimento de pólos regionais, visando, prover às regiões metropolitanas menores, integração de políticas públicas e melhor oferta de serviços urbanos, fortalecendo regiões e cidades com capacidade de melhor absorver o crescimento urbano e, proporcionar o desenvolvimento socioeconômico.

O Projeto Cidades do Ceará (Cariri Central) constitui, portanto, uma fórmula de investimento a ser replicada nas demais regiões do Estado. Através dele, pretende-se fortalecer o Cariri, transformando-o numa região capaz de dividir com a capital a atração de população, equipamentos, atividades, bens e serviços, e assim promover o desenvolvimento econômico; melhorar a infraestrutura urbana; e ampliar a capacidade de gestão regional do Cariri.

Os critérios utilizados para que essa região recebesse tais investimentos foram: os investimentos públicos já existentes na região; a existência de atividades produtivas competitivas para o Estado, como a indústria de calçados e o turismo; o elevado poder de atração de investimentos e de geração de empregos formais na região; a capacidade das atividades aqui realizadas em alavancar o desenvolvimento da região e o processo de polarização regional constituído por mais de um município, caracterizando uma região metropolitana.

O projeto irá executar obras que são consideradas estruturantes para o desenvolvimento das nove cidades. As obras são: Aterro consorciado regional, Avenida do Contorno (Juazeiro do Norte), Roteiro da Fé (Juazeiro do Norte), Recuperação Ambiental e Urbanização no Bairro Seminário (Crato), Requalificação das Praças Centrais (Crato), Requalificação da Área Central (Farias Brito), Centro Multifuncional de Serviços (Juazeiro do Norte), Serviços de Sinalização Turística do Geopark Araripe, Infraestrutura e Melhorias dos Geossítios do Geopark Araripe. (CARTAXO, 2010, p. 02)

Além de cada Estado poder definir seus critérios específicos para a criação e beneficiamento das regiões metropolitanas, os mesmos também têm autonomia para a gestão metropolitana, com a finalidade de maior integração. 
A infra-estrutura de transporte passou a ser vista primordialmente como apoio necessário á consolidação da integração economica, através da incorporação de vazios economicos e recuperação das regiões menos desenvolvidas, estagnadas ou decadentes. De certa forma,o desenvolvimento regional e a localização industrial passaram a ter seu planejamento condicionado...(BARAT, 2007, vol. I, p. 16)

Recentemente o trecho da Rodovia Padre Cícero, que vai encurtar o trajeto entre o Cariri e a Capital do estado em 70Km, foi inaugurado. A implantação do trecho da rodovia CE-385, ligando o Município de Caririaçu ao distrito de Quitaiús, em Lavras da Mangabeira, oferece agora melhores condições de tráfego e escoamento de produção do cariri que já dispunha de uma posição privilegiada em relação às demais capitais do Nordeste.

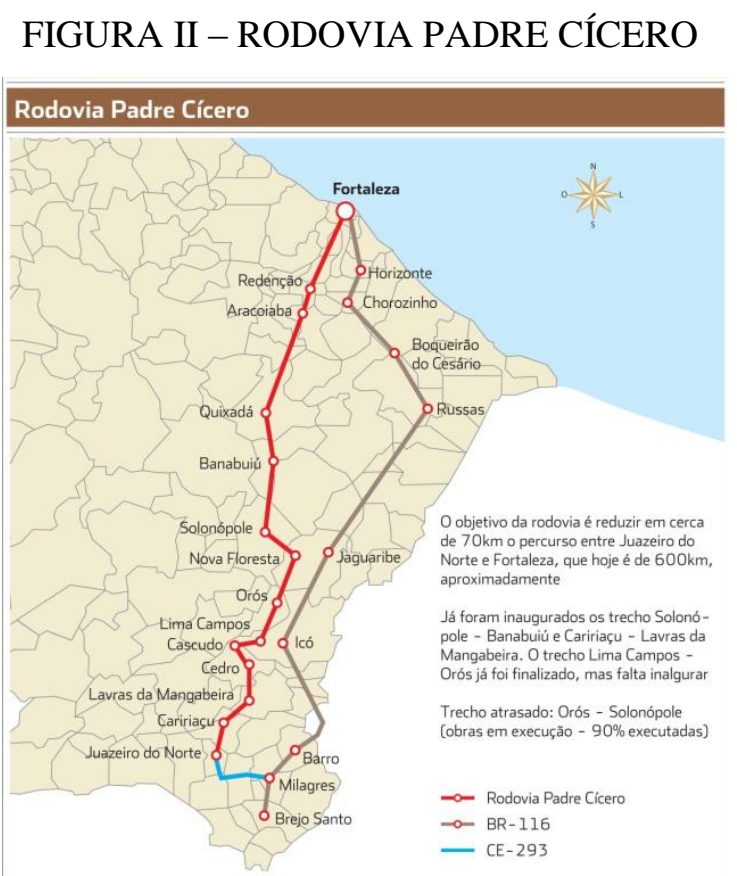

Fonte: Diário do Nordeste

\section{Ações e Prioridades para a Região}

Embora fique claro como principal foco do desenvolvimento na região dois setores econômicos, calçado e turismo, alguns projetos de avanços trazem em sua concepção, uma série de ações mais do que bem vindas, seja na área de infra-estrutura, de inovação ou tecnologia. Em todas as áreas citadas, procedem diferentes níveis de preocupações com a necessidade de se tentar maximizar os impactos positivos que se espera dos investimentos, e de se evitar, eventuais impactos negativos.

Entretanto, um fator importante para o êxito, na região, foi a adesão do setor industrial, mais especificamente no ramo de calçados, segundos dados do Serviço Brasileiro de Apoio as Micro e Pequemas Empresas - SEBRAE, o Arranjo Produtivo Local (APL) de Calçados do Cariri encerrou 
2010 com 112 empresas e para 2011, a ideia era investir em mais tecnologia, inovação e informação. Se em 2010 as ações eram na sua maioria voltadas à gestão, já no $1^{\circ}$ trimestre de 2011, com o auxílio de algumas consultorias, foram adequadas a um novo foco que mira o mercado consumidor, o ambiente externo e os resultados.

A realidade do Cariri fez com que os critérios utilizados para a seleção das intervenções e ações que integram a Região Metropolitana do Cariri fossem suficientemente abrangentes, com objetivos, para contemplar, todas as divergências dos municípios envolvidos, como ressalta Nojima sobre desenvolvimento regional $(2008$, p. 82) "[...] busca lidar com a diversidade do desenvolvimento no espaço nacional". De modo geral, pode-se considerar como requisitos os seguintes: - Contribuição para o fortalecimento das regiões como um todo; - Cidade com maior influência na região; Viabilidade econômica e financeira; - Sustentabilidade sócio-ambiental; - Recursos para viabilização.

As ações e Prioridades devem possuir foco em: constituir um pólo estratégico de desenvolvimento socioeconômico e ambiental na região do Cariri, com base em suas potencialidades, voltadas para a criação de novas oportunidades de geração de emprego e renda e para a redução das desigualdades. No entanto, um fator de importante relevância deve ser levando em consideração, o tempo, o processo de implantação das ações que partem da iniciativa pública nem sempre demanda de um cronograma em curto prazo, levam certo período para serem postos em prática.

O tempo é um fator de importância considerável em qualquer processo visando ao desenvolvimento, segundo se verifica pela experiência da iniciativa privada em relação a governamental e o atraso dos países onde a primeira depende mais da segunda devido a burocracia estatal, a começar pelas práticas legislativas e complementares; dias, meses e, até, anos seguidos decorrem antes de preenchidos os requisitos...(NOBRE, 2001, p.299)

No contexto de uma política de desenvolvimento, a preocupação centra-se na elevação do nível de renda, na implantação de novas indústrias e na geração de novos empregos na economia como um todo, na visão de Nali (1993, p. 03) "no processo de desenvolvimento, espera-se que o livre jogo das forças de mercado provoque tanto o aumento da renda per capita, como sua melhor distribuição entre as classes sociais e as regiões do país." Contudo, tem-se demonstrado que o crescimento, pelo menos nas fases iniciais do processo de desenvolvimento, efetua-se com desigualdades regionais crescentes e deterioração do nível de vida da maioria da população, principalmente nas áreas tradicionalmente mais pobres.

A seguir temos dados do IBGE referente à desigualdade e pobreza, os números mostram a porcentagem da população de cada município que vive com menos de um salário mínimo por mês no ano de 2009, o que caracteriza a má distribuição da renda na época, portanto uma das prioridades agora deveria ser a reversão desse quadro buscando o equilíbrio. 
QUADRO V - MAPA DE POBREZA E DESIGUALDADE - MUNICÍPIOS BRASILEIROS 2009

\begin{tabular}{|l|l|}
\hline Juazeiro do Norte & $52,4 \%$ \\
\hline Crato & $44,3 \%$ \\
\hline Barbalha & $52,51 \%$ \\
\hline Nova Olinda & $60,12 \%$ \\
\hline Santana do Cariri & $71,78 \%$ \\
\hline Farias Brito & $63,78 \%$ \\
\hline Caririacu & $62,88 \%$ \\
\hline Missão Velha & $54,66 \%$ \\
\hline Jardim & $58,41 \%$ \\
\hline
\end{tabular}

Fonte: IBGE, 2009

As diferenças também se estendem as arrecadações de cada município, o que também deve ser observado.

QUADRO VI - RECEITAS ORÇAMENTÁRIAS - 2009

\begin{tabular}{|c|c|}
\hline Juazeiro do Norte & $217.826 .545,51$ \\
\hline Crato & $109.586 .023,55$ \\
\hline Barbalha & $86.779 .801,18$ \\
\hline Nova Olinda & $16.953 .786,20$ \\
\hline Santana do Cariri & $21.836 .854,44$ \\
\hline Farias Brito & $24.320 .279,88$ \\
\hline Caririaçu & $34.965 .739,80$ \\
\hline Missão Velha & $33.328 .457,13$ \\
\hline Jardim & $31.016 .079,37$ \\
\hline
\end{tabular}

Fonte: IBGE, 2009

\section{A Administração Pública}

Na nossa região, tradicionalmente, existem os chamados serviços públicos: água, iluminação pública, coleta de lixo, limpeza de ruas, correios, entre outros. Saber quando e por que atividades como essas são consideradas serviço público constitui uma dúvida se o mesmo está sendo oferecido afim de melhorar a vida da sociedade ou apenas como ferramenta de campanhas eleitorais. Os auxílios econômicos concedidos pelas políticas de desenvolvimento implicam em um desembolso efetivo de dinheiro do estado em favor da sociedade local, estes não impõem aos governos locais um desembolso imediato, mas promovem uma maior captação de recurso a longo prazo. O fato em questão é, que a RMC, traz consigo melhorias consideráveis para a economia, no entanto, o custo de vida efetivo de um cidadão irá aumentar, como mostra estudos realizados pela Fundação Getúlio Vargas em regiões metropolitanas recém formadas. 
Finalidades diversas levam o legislador a considerar certa atividade como serviço publico, seja para retirar da especulação privada setores delicados, para que o benefício do serviço alcance os menos favorecidos, para suprir a deficiencia da iniciativa privada ou mesmo para atender a fins fiscais ou favorecer o progresso técnico. (MELLO, 2003, p. 51).

Apesar das recentes atenções voltadas para a expansão regional, sabe-se que a oferta de infra-estrutura urbana tem se mostrado incompatível com as exigências do desenvolvimento que se esperava da mesma. Após anos de políticas com visão a curto prazo acarretaram a degradação do patrimônimo construído no passado e a falta de conclusão das expanssões previstas, como centro de apoio aos romeiros em juazeiro do norte, o centro de convenções em Crato, a revitalização da CE 292.

A estruturação do Estado Brasileiro voltou-se para o desenvolvimento no seu sentido mais amplo, atuando vale repetir, não so pelo provimento das infra-estruturas, como por um importante participação na produção de insumos básico. $\mathrm{Na}$ verdade o estado assumiu um papel de empreendedor não por razões ideológicas, mas sim como um meio pragmático de dinamizar o processo de desenvolvimento. (BARAT, 2007, vol. II, p. 09)

A compreensão que o Governo tem sobre a necessidade de ampliar e fortalecer o processo de desenvolvimento sócio-econômico e de urbanização do Cariri, de forma a dar início a um processo de descentralização da região metropolitana de Fortaleza, minimizar as disparidades socioeconômicas entre esta e as demais regiões do Estado, proporcionando maior equilíbrio na oferta de oportunidades de trabalho e renda, estruturando a economia da RMC como fator fundamental para a redução da desigualdade.

O Estado do Ceará vem experimentando nas últimas décadas um acelerado processo de urbanização, que supera o verificado no Nordeste e se aproxima rapidamente da taxa nacional. Esse fato ganha realce quando se constata que, no tocante ao crescimento populacional do Estado, os índices têm se situado abaixo do que se observa no restante do país e na Região Nordeste. Esse processo de urbanização, associado a uma profunda desigualdade social, vem gerando um preocupante quadro de desequilíbrio regional, requerendo de sucessivas administrações, esforços para a institucionalização de uma política de desenvolvimento estadual consistente e capaz de reverter essa realidade, na qual se destacam quatro grandes problemas. (CARTAXO, 2009. p. 15)

\section{Perspectivas de Crescimento da RMC}

O momentos vivenciados pela RMC, visa a estabilidade e o fomento do crescimento da sua economia, no entanto, nesse processo de desenvolvimento a integração dos jovens empresários que surgirão junto ao crescimento da região, tornam-se fundamentais no processo, apresentar vantagens como a de aguçar-lhes o senso de responsabilidade social, devendo resultar, em princípio, do ambiente familiar, onde a voção, ou herança, se manifesta e torna-se impulso para o desempenho de uma 
atividade correta, não deixando de suprimir as raízes locais, o que vem a gerar a perda de identidade do empreendedor caririense.

O fundamento da empresa já não é mais , seguramente, o patrimonial, que a caracterizava como um bem de família, no sentido restrito, nem, muito menos, o objetivo principal por ela perseguido é o lucro, para cuja obtenção encontra muitos obestaculos, de ordem social, fiscal, etc. (NOBRE, 2001, p. 352)

Não obstante a este fato, a busca de reversão do quadro de desequilíbrio e desigualdade entre a região metropolitana da capital do estado e as demais localidades, tem sido influenciada principalmente pelos seguintes fatores: a perspectiva de progressiva urbanização e a necessidade de interiorizar o desenvolvimento, consolidando regiões e cidades potencialmente multiplicadoras de investimentos. A interiorização desse desenvolvimento deverá ser realizada através do fortalecimento econômico buscando a estruturação física dos municípios beneficiários da RMC, visando redução das desigualdades de modo geral. Considerando a implantação de um conjunto de ações na região do Cariri, são beneficiários diretos todos os que atuam nos setores, públicos ou privados, envolvidos nos eixos da região. Como beneficiários indiretos podem ser identificados os 497.782 habitantes residentes nas áreas de atuação, que correspondem a 6,7\% da população do Estado.

Como principal perspectiva, podemos destacar o seguinte fato: em conferir prioridade de investimento a um grupo de cidades, tormando-as capazes de absorver o crescimento urbano regional, simultaneamente, viabilizar o desenvolvimento socioeconômico do interior, de forma a atrai atividades e mão de obra capacitada.

\section{Desenvolvimento Sustentável}

A definição mais aceita para esse tipo de avanço é, "o desenvolvimento capaz de suprir as necessidades da geração atual, sem comprometer a capacidade de atender as necessidades das futuras gerações", segundo a WWF Brasil, uma ONG brasileira, participante de uma rede internacional e comprometida com a conservação da natureza dentro do contexto social e econômico. Essa definição surgiu na Comissão Mundial sobre Meio Ambiente e Desenvolvimento, criada pelas Nações Unidas para discutir e propor meios de harmonizar dois objetivos: o desenvolvimento econômico e a conservação ambiental, portanto a região do Cariri deve levantar essa bandeira haja vista que se localiza numa das mais antigas áreas de proteção ambiental do país, a FLONA.

A seguir podemos observar as descrições de indicadores dos investimentos que serão realizados na RMC. 
QUADRO VII - INDICADORES DOS INVESTIMENTOS

\begin{tabular}{|c|c|c|c|}
\hline $\begin{array}{l}\text { OBJETIVO DO } \\
\text { PROJETO }\end{array}$ & & INDICADORES DE RESULTADO & $\begin{array}{l}\text { FINALIDADE DA INFORMACÃO } \\
\text { FORNECIDA PELO INDICADOR }\end{array}$ \\
\hline \multirow{5}{*}{$\begin{array}{l}\text { Promover o } \\
\text { desenvolvimento } \\
\text { econômico, melhorar a } \\
\text { infra-estrutura urbana e } \\
\text { aumentar a capacidade } \\
\text { de gestão regional na } \\
\text { região do Cariri Central, } \\
\text { no Ceará, que inclui os } \\
\text { seguintes municipios: } \\
\text { Barbalha, Caririaçu, } \\
\text { Crato, Farias Brito, } \\
\text { Jardim, Juazeiro do } \\
\text { Norte, Missão Velha, } \\
\text { Nova Olinda e Santana } \\
\text { do Cariri. }\end{array}$} & 1 & $\begin{array}{l}\text { Redução percentual no tempo médio de } \\
\text { deslocamento (hora de pico do trânsito) } \\
\text { entre pontos específicos da região } \\
\text { central de Juazeiro do Norte (de } 15 \% \text { ). }\end{array}$ & $\begin{array}{l}\text { Ajudar a medir a efetividade do } \\
\text { investimento em rodovias secundárias e a } \\
\text { necessidade de outras para a região } \\
\text { (Barbalha, por exemplo). }\end{array}$ \\
\hline & 2 & $\begin{array}{l}\text { Aumento percentual de resíduos sólidos } \\
\text { gerados pelas famílias do Cariri Central } \\
\text { depositados apropriadamente }{ }^{16} \text { no Aterro } \\
\text { Regional (até } 85 \% \text { ). }\end{array}$ & $\begin{array}{l}\text { Fornecer informações acerca da efetividade } \\
\text { do consórcio e dos investimentos privados } \\
\text { na oferta de serviços públicos. }\end{array}$ \\
\hline & 3 & $\begin{array}{l}\text { Aumento percentual da produção anual } \\
\text { de calçados (número de pares) da região } \\
\text { do Cariri Central. }\end{array}$ & \multirow{2}{*}{$\begin{array}{l}\text { Informar sobre a efetividade das ações de } \\
\text { Desenvolvimento Econômico Local } \\
\text { propostas, e sobre o aumento da } \\
\text { competitividade regional. }\end{array}$} \\
\hline & 4 & $\begin{array}{l}\text { Aumento percentual do número de } \\
\text { turistas que visitam o Cariri Central por } \\
\text { mês/ano (até } 20 \% \text { ). }\end{array}$ & \\
\hline & 5 & $\begin{array}{l}\text { Operacionalização de um modelo de } \\
\text { gestão regional para o Cariri Central }{ }^{17} \text {. }\end{array}$ & $\begin{array}{l}\text { Possibilitar o acompanhamento do } \\
\text { progresso do trabalho conjunto das } \\
\text { instâncias de representação regional e } \\
\text { demais líderes da sociedade civil rumo ao } \\
\text { desenvolvimento regional do Cariri. }\end{array}$ \\
\hline $\begin{array}{l}\text { RESULTADOS } \\
\text { INTERMEDIÁRIOS }\end{array}$ & \multicolumn{2}{|r|}{$\begin{array}{l}\text { INDICADORES DE RESULTADO } \\
\text { INTERMEDIÁRIOS } \\
\text { (Indicadores de produto) }\end{array}$} & $\begin{array}{l}\text { FINALIDADE DA INFORMAÇÃO } \\
\text { FORNECIDA PELO INDICADOR }\end{array}$ \\
\hline \multirow{3}{*}{$\begin{array}{l}\text { 1. Melhoria da infra- } \\
\text { estrutura regional e } \\
\text { municipal na Região } \\
\text { Central do Cariri. }\end{array}$} & 1.1 & $\begin{array}{l}\text { Construção e pavimentação da Av. de } \\
\text { Contorno, em Juazeiro do Norte. }\end{array}$ & \multirow{3}{*}{$\begin{array}{l}\text { Este conjunto de indicadores possibilitará o } \\
\text { monitoramento do progresso da } \\
\text { implementação e da efetividade dos } \\
\text { investimentos no fomento de mudanças } \\
\text { físicas na região. }\end{array}$} \\
\hline & 1.2 & $\begin{array}{l}\text { Implementação do Aterro Sanitário } \\
\text { Regional de acordo com o projeto } \\
\text { executivo. }\end{array}$ & \\
\hline & 1.3 & $\begin{array}{l}\text { Conclusão das obras do Museu no } \\
\text { Engenho Tupinambá, em Barbalha. }\end{array}$ & \\
\hline \multirow{3}{*}{$\begin{array}{l}\text { 2. Melhoria da } \\
\text { Competitividade dos } \\
\text { APLs de turismo e } \\
\text { calçados }\end{array}$} & 2.1 & $\begin{array}{l}\text { Número de cursos / capacitações } \\
\text { organizados pelo Projeto, voltados para } \\
\text { o APL de calçados. }\end{array}$ & \multirow{3}{*}{$\begin{array}{l}\text { Este conjunto de indicadores possibilitará o } \\
\text { monitoramento do progresso das atividades } \\
\text { de LED (Desenvolvimento Econômico } \\
\text { Local), focadas nos APLs de calçados e } \\
\text { turismo. }\end{array}$} \\
\hline & 2.2 & $\begin{array}{l}\text { Número de cursos / capacitações } \\
\text { organizados pelo Projeto, voltados para } \\
\text { o APL de turismo. }\end{array}$ & \\
\hline & 2.3 & $\begin{array}{l}\text { Número de iniciativas para o Geopark } \\
\text { Araripe implementadas }{ }^{18} \text {. }\end{array}$ & \\
\hline
\end{tabular}

Fonte: Projeto Cidades do Cariri - 2010

Desenvolvimento é confundido com crescimento econômico, que depende do consumo crescente de energia e recursos naturais. Esse tipo de desenvolvimento tende a ser insustentável, pois leva ao esgotamento dos recursos naturais dos quais a humanidade depende. Segundo a WWF "O desenvolvimento sustentável sugere, de fato, qualidade em vez de quantidade, com a redução do uso de matérias-primas e produtos e o aumento da reutilização e da reciclagem."

Neste contexto, pensar em sociedade sustentável significa ampliar as preocupações para todas as dimensões do desenvolvimento. Pode-se dizer que o conceito de sustentabilidade aborda outras áreas das atividades humanas além da ecológica, tais como a econômica, a social, a espacial, a cultural, a tecnológica e a política. 


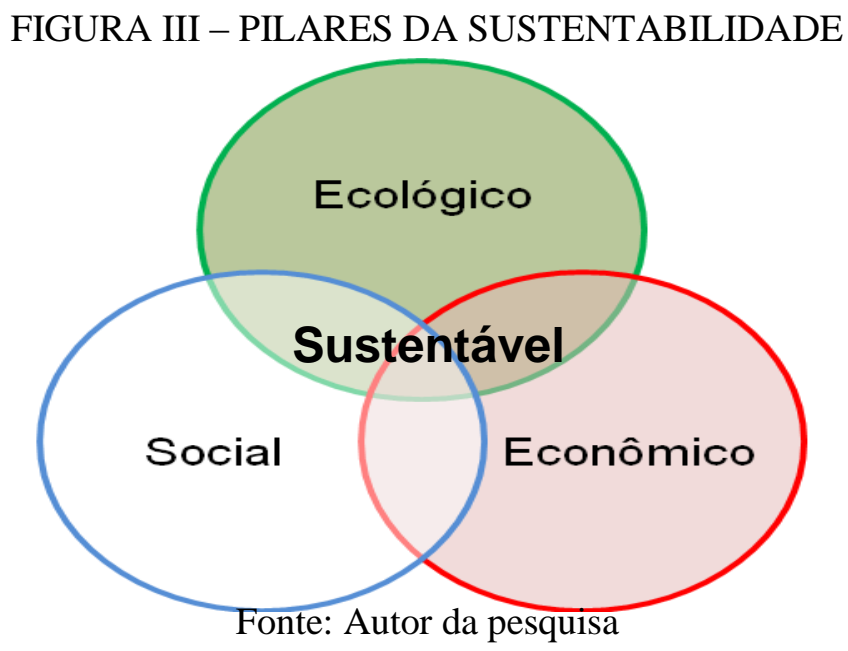

Para a população do Cariri não resta dúvida de que os investimentos aqui realizados são importantes, entretanto, o trato com o meio ambiente deve ser assegurado para que gerações futuras da região possam desfrutar de suas belezas naturais como o Geopark Araripe, o Soldadinho do Araripe, a Chapada, enfim, entre outros.

A Secretaria das Cidades é uma das principais apoiadoras do projeto Geopark Araripe, com investimentos em projetos de estruturação dos geossítios, material de apoio, junto como Ministério da Integração Nacional, na construção da sede do Geopark Araripe e aquisição de mobiliário e equipamentos, entre outros.(GEOPARK, 2001.)

\section{Método}

O desenvolvimento da presente pesquisa utilizou a metodologia de caráter bibliográfico, através de livros, artigos, trabalhos de grau, projetos, sites e vídeos.

Como foco central teve o desenvolvimento da Região Metropolitana do Cariri e sua importância para o estado do Ceará e seus habitantes. A fim de atender ao objetivo proposto, a pesquisa valeu-se de uma abordagem exploratória.

O objetivo de uma pesquisa exploratória é familiarizar-se com um assunto ainda pouco conhecido, pouco explorado. Ao final de uma pesquisa exploratória, você conhecerá mais sobre aquele assunto, e estará apto a construir hipóteses. Como qualquer exploração, a pesquisa exploratória depende da intuição do explorador (neste caso, da intuição do pesquisador)... Como qualquer pesquisa, ela depende também de uma pesquisa bibliográfica, pois mesmo que existam poucas referências sobre o assunto pesquisado, nenhuma pesquisa hoje começa totalmente do zero. Haverá sempre alguma obra, ou entrevista com pessoas que tiveram experiências práticas com problemas semelhantes ou análise de exemplos análogos que podem estimular a compreensão. (JOSÉ, 2010, p.1) 
O Motivo pelo qual optou-se por este tipo de pesquisa deve-se ao fato de a mesma tem como principal objetivo o fornecimento de critérios sobre a situação-problema, ou seja, o trabalho é abastecido por dados e informações que apos processados facilitam a compreensão, diferente de uma pesquisa descritiva que possuem como objetivo a descrição das características o que inviabilizaria o desenvolvimento do estudo tendo em vista que o desenvolvimento da região é um fato ainda inexplorado pois os resultado dos investimento aqui feito apenas serão notado no futuro. Por tanto os elementos bibliográficos aqui existentes tem como principal objetivo documentar o desenvolvimento da RMC, ou ate mesmo servir como referência, auxiliando estudo futuros que venham a ser realizados sobre o tema.

O pesquisador vai testar as hipóteses, que só podem ser confirmadas por dados e informações futuras, decorrentes da experiência. Em outras palavras... o pesquisador tem controle e possibilidade de manipular os dados para obter novas informações. (JOSE, 2010, p. 7)

\section{Conclusão}

O desenvolvimento chegou de fato à região do Cariri, não restam dúvidas que os projetos e incentivos governamentais irão prover um avanço considerável, constituindo um pólo estratégico de desenvolvimento regional, com base em suas potencialidades, voltadas para a criação de novas oportunidades.

Prospectando benefícios diretos e indiretos para cerca de 540 mil habitantes residentes na RMC, serão investidos milhões de reais, com a chamada interiorização do desenvolvimento, que deverá ser realizada através do fortalecimento econômico, visando redução das desigualdades de modo geral.

Tal desenvolvimento econômico ocorre de modo muito concentrado, enquanto a região metrópole cresce rapidamente, as demais permanecem estagnadas e perdem participação no entorno metropolitano, assim os fatores de produção, como capital e mão-de-obra, tendem a emigrar das cidades periféricas em direção do pólo.

$\mathrm{O}$ crescimento da RMC fica atrelado às políticas públicas, tendo como foco principal a administração pública das cidades do triangulo CRAJUBAR, e fica à cargo da população exigir equilibrado realce aos vários objetivos, especialmente no que tange à melhor distribuição dos recursos. O que fica claro e evidente é que para se estabelecer uma política de desenvolvimento em meio urbano, não é suficiente apenas investimentos em geração de emprego e renda, mas tornam-se necessárias também ações globais de melhoria da qualidade de vida, políticas habitacionais e projetos 
de avanço das cidades. O objetivo principal deveria ser um avanço compartilhado, levando em consideração as diferenças entre as cidades e suas potencialidades, pois as diferenças são evidentes e políticas conjuntas devem priorizar o desenvolvimento da região como um todo.

Falando em políticas conjuntas não se pode esquecer o ambiente no qual a região está inserida, pois todos desfrutam de suas vantagens, sobretudo logísticas, e grande parte população do Cariri está convicta que os investimentos aqui realizados são importantes com destaque nos setores de Meio Ambiente, Agronegócios, Logística, Construção Civil, Comércio Exterior, Energias Renováveis, Educação, Indústria, Serviços, Tecnologia de Informação e Turismo, entretanto o trato com o meio ambiente deve ser assegurado para que gerações futuras possam desfrutar de das belezas naturais regionais.

Por fim ressalta-se que o presente estudo obteve êxito, pois teve como objetivo principal identificar, através de pesquisa bibliográfica, os principais investimentos de iniciativa pública ou privada para a consolidação da Região Metropolitana do Cariri, a fim de documentar e expressar para a população interessada os motivos pelo o qual o Cariri tornou-se nos últimos anos em um verdadeiro canteiro de obras.

Sugere-se que mais estudos detalhados acerca do desenvolvimento regional da citada região sejam realizados, não somente com o propósito de documentar este potencial desenvolvimento, mas também para servir de fonte de avaliação das significativas transformações ocorridas ao longo do tempo na RMC. Durante o estudo pode-se notar a carência de informações sobre o assunto proposto, o mesmo sendo relativamente novo e com pouco material a disposição.

\section{Referências}

BARAT, Josef. Logística, transporte e desenvolvimento econômico: a visão histórica, vol. I, São Paulo: Editora CLA, 2007.

Logística, transporte e desenvolvimento econômico: a visão institucional, Vol. II, São Paulo: Editora CLA, 2007

Logística, transporte e desenvolvimento econômico: a visão macroeconômica, Vol. III, São Paulo: Editora CLA, 2007

Logística, transporte e desenvolvimento econômico: a visão setorial, Vol. IV, São Paulo: Editora CLA, 2007. 
CARTAXO, Joaquim. Projeto cidades do Cariri, 2009. 114f. Projeto (Projeto de desenvolvimento Regional). Fortaleza.

Governo do estado discute região metropolitana do Cariri. Agropolos do Ceará, Fortaleza, 11/05/2010. Editoral, Noticias, p. 01.

DIÁRIO DO NORDESTE, Fortaleza: 2012. Caderno regional. Disponível em: < http://diariodonordeste.globo.com/caderno.asp?codigo=16\&CodigoEd= >. Acesso em: 15 Jan. 2012.

FGV. Fundação Getulio Vargas. Descrição de bases de dados, 2011. Disponível em: < http://portal.fgv.br/ptBr/busca?cx=010578076968944729182\%3Atuq_vfqmc10\&cof=FORID\%3A11 \&query=regiao+metropolitana\&form_build_id=form-e7e1e5fc2d7d65210980d4f0b9 b3e90f\&form_token=6c4f515060f3557c6ee5b2a0875b5060\&form_id=google_cse_results_searchbox _form >. Acesso em: 19 nov. 2011.

GEOPARK, Araripe. Secretário das Cidades aborda Geopark Araripe em palestra, 2011. Disponível em: $\quad$ e $\quad$ http://www.geoparkararipe.org.br/geoparkwebsite/newsCommand.do?METHOD_KEY=findNewsByID\&newsID=386 > . acesso: 15 Jan 2012.

IBGE. Instituto Brasileiro de Geografia e Estatística. Indicadores, 2012. Disponível em :< http://www.ibge.gov.br/home/mapa_site/mapa_site.php\#indicadores >. Acesso 15 jan 2012.

JOSÉ, Carlos Giudice dos Santos. TIPOS DE PESQUISA, 2010. Diponivel em: < www.oficinada pesquisa.com.br >. Acesso 24 fev 2012.

JOTALOPES. Juazeiro do Norte - CE: CALÇADOS NO CARIRI Fetecc deverá gerar R\$ 9 mi em negócios, 2011. Disponivel em < http://www.caririnoticia.com.br/2011/05/juazeiro-do-norte-cecalcados-no-cariri-fetecc-devera-gerar-r-9-mi-em-negocios.html >. Acesso 23 fev 2012.

MELLO, Célia Cunhas. O fomento da administração pública, Belo Horizonte: Del Rey, 2003.

NOBRE, Geraldo da Silva. O Processo histórico de industrialização do Ceará/Geraldo da silva Nobre. 2ed. rev. e ampl. Fortaleza: FIEC, 2000

NOJIMA, Daniel. Teoria do desenvolvimento e economia regional: uma análise da experiência brasileira, 1995-2005. 197f. Tese (doutorado Programa de Pós-Graduação em Desenvolvimento Econômico) Universidade Federal do Paraná, Curitiba. 
ONU. Organização das Nações Unidas. A ONU e os direitos humanos, 2012. Disponivel em: < http://www.onu-brasil.org.br/ >. Acesso em: 15 Jan. 2012.

PERFIL socioeconômico. Prefeitura de Juazeiro do Norte, Juazeiro do Norte, 24 de fevereiro 2012. Secretaria. Seplad, p1. Disponível em:< http://www.juazeiro.ce.gov.br/ secretaria/seplad/perfil_socioeconomico > acesso 24 fevereiro 2012.

SANTANA, Manoel. Foco para odesenvolvimento. Diário do Nordeste, Fortaleza, 11/06/2009. Regional, p. 01.

SEBRAE. Serviço Brasileiro de Apoio a Micro e Pequenas Empresas. Setor de calçados do Cariri muda gestão com tecnologia, 2011. Disponível em: < http://agenciasebrae.com.br/noticia/11591427/economia/setor-de-calcados-do-cariri-muda-gestaocom-tecnologia/ >. Acesso em: 19 nov. 2011.

SOUZA, Nali de Jesus de. Economia regional: Conceito e fundamentos teóricos, 2005. 22f. Artigo (Artigo cientifico de economia). UFRJ, Rio de Janeiro.

YAÇANÃ, Nepomucena. Região Metropolitana do Cariri: Economista aponta desafios, 2011. Jornal Diário do Nordeste, Fortaleza. Disponível em: < http://www.vejajuazeiro.com.br/ >. Acesso em: 24 fev. 2012.

WWF-Brasil. O que é desenvolvimento sustentável? 2012. Disponível em: < http://www.wwf.org.br/natureza_brasileira/questoes_ambientais/desenvolvimento_sustentavel/ > Acesso em: 05 Jan. 2012.

\section{Sobre os Autores:}

(1) Raimundo Pereira Aguiar Neto é Bacharel em Administração de Empresas pela Universidade Estadual vale do Acaraú - UVA;

1. Michele da Silva Teixeira é Bacharel em Administração de Empresas e Pós-Graduada em Docência do Ensino Superior pela Faculdade Vale do Jaguaribe - FVJ.

E-mail: michelesilvaadm@bol.com.br

\section{Como citar este artigo (Formato ISO):}

AGUIAR NETO, R.P. e TEIXEIRA, M.S. Desenvolvimento Regional: um estudo na Região Metropolitana do Cariri. Id on Line Revista de Psicologia, Novembro de 2012, vol.1, n.18, p. 13-32. ISSN 1981-1189. 